\title{
Colorectal Adenoma with Severe Dysplasia
}

National Cancer Institute

\section{Source}

National Cancer Institute. Colorectal Adenoma with Severe Dysplasia. NCI Thesaurus.

Code C5685.

An adenoma that arises from the colon or rectum. It is characterized by the presence of severe epithelial dysplasia. 